\title{
Comparison of the Viability and Yield of Adipose-Derived Stem Cells (ASCs) from Different Donor Areas
}

\author{
ANASTASIOS TSEKOURAS ${ }^{1}$, DIMITRIOS MANTAS ${ }^{2}$, DIAMANTIS I. TSILIMIGRAS ${ }^{3}$, \\ DEMETRIOS MORIS ${ }^{4}$, MICHAEL KONTOS ${ }^{5}$ and GEORGE C. ZOGRAFOS ${ }^{6}$ \\ ${ }^{1}$ Department of Plastic Surgery, 'Leto' Obstetrics, Gynaecology and Surgery Center, Athens, Greece; \\ ${ }^{2}$ Second Propaedeutic Department of Surgery, 'Laikon' General Hospital, School of Medicine, \\ National and Kapodistrian University of Athens, Athens, Greece; \\ ${ }^{3}$ School of Medicine, National and Kapodistrian University of Athens, Athens, Greece; \\ ${ }^{4}$ Department of Surgery, Division of Surgical Oncology, The Ohio \\ State University Wexner Medical Center, Columbus, OH, U.S.A.; \\ ${ }^{5}$ First Department of Surgery, 'Laikon' General Hospital, School of Medicine, \\ National and Kapodistrian University of Athens, Athens, Greece; \\ ${ }^{6}$ First Propaedeutic Department of Surgery, 'Hippocration' Hospital, \\ School of Medicine, National and Kapodistrian University of Athens, Athens, Greece
}

\begin{abstract}
Background: Adipose tissue contains variable amounts of stem cells that have recently attracted increased interest due to their strong proliferative and differentiation capacity. However, significant heterogeneity exists in terms of stem cell yield and viability profile among individuals as well as different donor areas. Materials and Methods: Between June 2016 and July 2016, forty (40) women underwent outpatient cosmetic liposuction procedures conferring a total of 53 lipoaspirates; inner thigh $(n=13)$, outer thigh $(n=9)$, abdomen $(n=9)$, waist $(n=16)$ and inner knee $(n=6)$. Lipoaspirates were harvested using a tulip low-pressure syringe lipoaspiration system with a diameter of $3 \mathrm{~mm}$. Centrifugation separated adipocytes from the stromal vascular fraction $(S V F)$. Isolation of the adipose-derived stem cells (ASCs) was achieved through culture of the SVF. Viability of SVF cells and ASCs was evaluated with trypan blue dye under microscope and using flow cytometry with 7-AAD staining, respectively. Total cell count was estimated for both the SVF and ASCs. Results: Outer thigh exhibited significantly higher SVF cell count compared to any other donor site $(p<0.05)$. In addition, inner and outer
\end{abstract}

This article is freely accessible online.

Correspondence to: Diamantis I. Tsilimigras, MD, School of Medicine, Natinonal and Kapodistrian University of Athens, 75 Mikras Asias str., 11527, Athens, Greece. Tel: +30 2107716042, e-mail: tsilidiam@gmail.com

Key Words: Fat grafting, adipose-derived stem cells, viability, yield, donor areas. thigh showed a significantly higher number of ASCs compared to abdominal, waist, and inner knee samples $(p<0.05)$. Finally, viability of SVF cells (range, 94-95\%) and ASCs (range, 93.1296.14\%) was excellent with no significant differences among donor areas. Conclusion: Tissue-harvesting area is a strong determinant of the quality of the fat grafts. Compared to abdomen, waist and inner knee, thighs seem favorable in terms of viability profile and yield of SVF cells and ASCs. Further randomized controlled trials incorporating a larger cohort of patients are warranted in order to verify our results.

Over the last few years, autologous fat grafting has been at the forefront of aesthetic plastic surgery clinical practice, since it provides exceptional results for the treatment of soft-tissue contour deformities $(1,2)$. Similar to bone marrow, the adipose tissue is derived from the embryonic mesenchyme and contains a supportive stromal vascular fraction (SVF) that can be easily isolated (3). Typically, SVF from adipose tissue contains different types of cells, including endothelial cells, smooth muscle cells, pericytes, leukocytes and pre-adipocytes, otherwise named as adipose-derived stem cells (ASCs) (4).

The potential of ASCs to differentiate into diverse cell types both in vitro and in vivo, offers outstanding opportunities for their clinical application as therapeutic agents (5). In particular, preclinical studies have revealed their capacity to differentiate toward the osteogenic, adipogenic, myogenic, and chondrogenic lineages $(6,7)$. Nevertheless, adipose tissue displays a significant heterogeneity in terms of stem cell yield, proliferation, and differentiation capacity not only among individuals, but even when comparing different fat depots within one individual (8). 
To date, results from the literature on the optimal tissueharvesting site are rather contradictory, therefore posing an intriguing challenge in the field of cosmetic surgery. In the present study, we sought to investigate whether the donor site affects the yield of stromal and adipose-derived stem cells obtained as well as their functional characteristics.

\section{Materials and Methods}

Study protocol and donor sites. The human lipoaspirates were prospectively harvested from 40 women that underwent outpatient cosmetic liposuction procedures on a private basis between June 2012 and July 2016. Some participants conferred fat samples from different regions comprising a total of 53 lipoaspirate samples; inner thigh $(n=13)$, outer thigh $(n=9)$, abdomen $(n=9)$, waist $(n=16)$ and inner knee $(n=6)$. Lipoaspirates were harvested using a tulip lowpressure syringe lipoaspiration system. Blunt-tipped liposuction cannulae with a diameter of $3 \mathrm{~mm}$ having small holes near the tip were used. All interventions were performed by a single senior plastic surgeon (A.T) and all samples were processed directly. All participants signed a written consent form and agreed beforehand to participate in the study. The study protocol was in accordance with the World Medical Association Declaration of Helsinki and an approval from our Institutional Review Board was obtained.

Isolation of the SVF and assessment of viability. After harvesting, lipoaspirate samples (Mean volumes of samples are presented on Table I) were directly washed with phosphate-buffered saline (PBS) and then centrifuged at $400 \times \mathrm{g}$ for $15 \mathrm{~min}$. Following removal of the oil, the lipid phase of the lipoaspirate from the top of the tube was obtained and diluted with an equal volume of collagenase digestion solution (Collagenase NB 4G proved grade; SERVA Electrophoresis, Heidelberg, Germany). After 25 min of incubation, an equal volume of Dulbecco's Modified Eagle Medium (DMEM, Thermo Fisher Scientific, Waltham, MA, USA) containing 20\% fetal bovine serum was added to stop enzymatic digestion. The supernatant, containing adipocytes, was separated from the pellet, containing the stromal vascular fraction, with centrifugation. The isolated stromal vascular fraction was filtered through a $100-\mu \mathrm{m}$ nylon filter and then processed for density gradient by centrifugation with Histopaque-1077 (Sigma-Aldrich, St. Louis, MO, USA). Thereafter, the mononuclear cell layer was carefully aspirated and the total number of stromal vascular fraction cells was counted. Viability of SVF was evaluated using the Trypan blue exclusion assay. Cell suspension $(10 \mu \mathrm{l})$ was diluted $1: 1$ with $0.4 \%$ Trypan Blue solution (Thermo Fischer Scientific, CA, USA). Cells were counted using a hemocytometer under light microscopy and the percentage of live cells was calculated. All activities were performed under good manufacturing practice (GMP) standards.

Isolation of ASCs through SVF culture. Isolation of ASCs was achieved through stromal vascular fraction culture. In brief, $1 \times 10^{7}$ SVF cells and $20 \mathrm{ml}$ of pre-warmed Non-hematopoietic Expansion Medium (Miltenyi Biotec, Auburn, CA, USA) containing 1\% of penicillin-streptomycin (Miltenyi Biotec, Auburn, CA, USA) were added to a $75-\mathrm{cm}^{2}$ cell culture flask and cultivated at $37^{\circ} \mathrm{C}, 5 \% \mathrm{CO}_{2}$, and $95 \%$ humidity. Following one day, non-adherent cells were removed by washing the flask with PBS. The adherent ASCs were cultured with the addition of fresh prewarmed $\left(37^{\circ} \mathrm{C}\right)$
Nonhematopoietic Expansion Medium (20 ml). The culture medium was replaced every two days and passaging was performed every 5 days. Briefly, cells were washed with PBS and detached after incubation with $0.5 \mathrm{mM}$ EDTA/0.05\% trypsin (Invitrogen, Carlsbad, CA, USA) at $37^{\circ} \mathrm{C}$ for $15 \mathrm{~min}$. Then, ASCs were washed with fresh Nonhematopoietic Expansion Medium and transferred to a new T25 flask $\left(1.25 \times 10^{5}\right)$ with $5 \mathrm{ml}$ of fresh Nonhematopoietic Expansion Medium. Finally, cell number was counted on each passage to calculate cell doubling time.

Detection of ASCs and assessment of viability. To characterize ASCs subpopulations from the fresh lipoaspirate samples, phenotype of cultured ASCs was examined after labeling with a panel of monoclonal antibodies against mesenchymal and hematopoietic stem cell markers (BD Biosciences, San Jose, California, USA) including stem cell markers (i.e. CD90 and CD105) and hematopoietic markers (i.e. CD45 and CD34). Briefly, $1 \times 10^{5} \mathrm{SVF}$ cells were stained with $0.05 \%$ CD90-PE-cy (PE-Cy ${ }^{\mathrm{TM}} 7$ Mouse AntiHuman CD90 Clone 5E10, BD Biosciences, USA) , 0.05\% CD105PerCP (PerCP-Cy ${ }^{\mathrm{TM}} 5.5$ Mouse anti-Human CD105 (Endoglin) Clone 266, BD Biosciences, USA), 0.2\% CD34-APC (APC Mouse Anti-Human CD34 Clone 581, BD Biosciences, USA), 0.2\% CD45PE (PE Mouse Anti-Human CD45 Clone HI30, BD Biosciences, USA) and 0.05 CD73-PE-cy (PE-Cy ${ }^{\text {TM }} 7$ Mouse Anti-Human CD73 Clone AD2, BD Biosciences, USA). After reacting with antibodies at $4^{\circ} \mathrm{C}$ for $30 \mathrm{~min}$, the cells were washed with PBS and analyzed by flow cytometry using BD FACSDiva software v6.1.3 (Becton Dickinson, San Jose, CA, USA). Viability of ASCs was assessed using the 7-Aminoactinomycin D (7-AAD) staining (Thermo Fisher Scientific, Waltham, MA, USA) with a flow cytometer.

Statistical analysis. Numerical data are presented as mean \pm standard deviation. Qualitative variables are presented as absolute and relative frequencies. All measurements were compared by using analysis of variance (ANOVA) followed by $t$-test. Statistical analysis was performed with the IBM SPSS v.22 statistical package. A value of $p \leq 0.05$ was considered significant and all $p$-values were two-sided.

\section{Results}

Study sample characteristics. All participants were females (40/40) with a mean age of 41.5 \pm 13.1 years, and an average body mass index (BMI) of $28 \pm 0.2 \mathrm{~kg} / \mathrm{m}^{2}$. Lipoaspirates were harvested from the inner thigh $(n=13)$, outer thigh $(n=9)$, abdomen $(n=9)$, waist $(n=16)$ and inner knee $(n=6)$. The average volume of lipoaspirate was $60.17 \pm 1.5 \mathrm{ml}, 67 \pm 0.8 \mathrm{ml}$, $51.67 \pm 1.1 \mathrm{ml}, 63.23 \pm 0.7 \mathrm{ml}$ and $58.75 \pm 1.1 \mathrm{ml}$ pertaining to the inner thigh, outer thigh, abdomen, waist and inner knee, respectively. No significant differences were noted regarding the sample volumes from the donor areas $(p=0.957)$.

Comparison of total cell yield (SVF/ASCs) from different donor sites. After extraction of the SVF from the lipoaspirates, the total number of SVF cells was counted for each region under investigation. The abdomen revealed 2.97 $( \pm 0.2) \times 10^{6}$ cells, the waist $5.61( \pm 0.31) \times 10^{6}$, the inner thigh $6.34( \pm 0.1) \times 10^{6}$, the outer thigh $12.31( \pm 1.2) \times 10^{6}$ and, finally, the inner knee $7.96( \pm 0.8) \times 10^{6}$ cells. No significant 
Table I. Total cell yield (SVF/ASCs) from different donor sites.

\begin{tabular}{lccc}
\hline Area & Mean volume $(\mathrm{ml})$ & Total cells before culture $(\mathrm{SVF})\left(\times 10^{6}\right)$ & Total cells after culture $(\mathrm{ASCs})\left(\times 10^{6} / \mathrm{ml}\right)$ \\
\hline Abdomen & $51.67 \pm 1.1$ & $2.97 \pm 0.2$ & $0.057 \pm 0.12$ \\
Waist & $63.23 \pm 0.7$ & $5.61 \pm 0.31$ & $0.088 \pm 0.33$ \\
Inner thigh & $60.17 \pm 1.5$ & $6.34 \pm 0.1$ & $0.105 \pm 1.1$ \\
Outer thigh & $67 \pm 0.8$ & $12.31^{*} \pm 1.2$ & $0.183^{* *} \pm 1.2$ \\
Inner knee & $58.75 \pm 1.1$ & $7.96 \pm 0.8$ & $0.09 \pm 0.9$ \\
\hline
\end{tabular}

*Outer thigh samples exhibited significantly higher yield of SVF cells than abdominal, waist, inner thigh and inner knee samples. **After culture of the SVF, outer thigh samples showed significantly higher yield of ASCs compared to abdominal, waist and inner knee samples but not inner thigh. SVF, stromal vascular facture; ASCs, adipose-derived stem cells.

Table II. Expression of surface antigens and assessment of viability of SVF cells and ASCs.

\begin{tabular}{lcccccc}
\hline Area & $\begin{array}{c}\mathrm{CD} 90^{+} \\
(\%)\end{array}$ & $\begin{array}{c}\mathrm{CD} 73^{+} \\
(\%)\end{array}$ & $\begin{array}{c}\mathrm{CD} 105^{+} \\
(\%)\end{array}$ & $\begin{array}{c}\mathrm{CD} 34-/ \mathrm{CD} 45^{-} \\
(\%)\end{array}$ & $\begin{array}{c}\text { Viability of SVF } \\
\text { cells (TB) }(\%)\end{array}$ & $\begin{array}{c}\text { Viability of ASCs } \\
(7-\mathrm{AAD})(\%)\end{array}$ \\
\hline Abdomen & $96.58 \pm 0.2$ & $94.57 \pm 0.5$ & $98.85 \pm 0.6$ & $1.31 \pm 0.1$ & $95 \pm 1.2$ & $93.12 \pm 1.2$ \\
Waist & $92.87 \pm 0.5$ & $93.92 \pm 0.7$ & $90.17 \pm 0.4$ & $1.25 \pm 0.3$ & $94.98 \pm 1.3$ & $96.14 \pm 1.4$ \\
Inner thigh & $92.02 \pm 1.1$ & $97.41 \pm 0.9$ & $96.88 \pm 0.5$ & $0.97 \pm 0.08$ & $94.11 \pm 0.8$ & $94.88 \pm 1.85$ \\
Outer thigh & $95.4 \pm 1.3$ & $89.8 \pm 1.4$ & $99.7 \pm 0.9$ & $0.88 \pm 0.07$ & $94.4 \pm 0.7$ & $97.4 \pm 0.7$ \\
Inner knee & $96.15 \pm 0.8$ & $96.43 \pm 1.6$ & $97.65 \pm 1.4$ & $0.02 \pm 0.01$ & $94 \pm 0.3$ & $96.5 \pm 0.6$ \\
\hline
\end{tabular}

SVF, Stromal vascular facture; ASCs, adipose-derived stem cells; TB, trypan blue; 7-AAD, 7-Aminoactinomycin D.

differences were observed among regions of liposuction with regard to number of SVF cells, except for the outer thigh samples, which exhibited significantly higher SVF cell count compared to any other donor sites $(p<0.05)$.

Isolation of ASCs was performed through SVF culture. The lowest cell yield per milliliter of liposuction tissue was observed in the abdominal samples $\left(0.057 \times 10^{6}\right.$ cells $\left./ \mathrm{ml}\right)$, whereas the highest yield was evident in the outer thigh samples $\left(0.183 \times 0^{6}\right.$ cells $\left./ \mathrm{ml}\right)$ followed by the inner thigh $\left(0.105 \times 10^{6}\right.$ cells $\left./ \mathrm{ml}\right)$ (Table I). Overall, between inner and outer thigh samples no significant difference was found with regard to the isolated ASCs, whereas outer thigh exhibited significantly higher number of ASCs compared to abdominal, waist, and inner knee samples $(p<0.05)$.

Expression of surface antigens and assessment of viability. Flow cytometry revealed that cultured ASCs positively expressed CD90 (range 92.02-96.58\%), CD73 (range 89.8$97.41 \%$ ) and CD105 (range 90.17-99.5\%), while negatively expressed CD34/CD45 (range 0.02-1.31\%) (Table II). Figure 1 is indicative of the expression of surface antigens in the outer thigh region. Cell viability was assessed twice; once with trypan blue dye on SVF and then using flow cytometry analysis for 7-AAD staining on ASCs. Concerning the SVF, all areas of liposuction showed an excellent profile of viability ranging from 94 to $95 \%$ with no significant differences among different areas. Similarly, staining with 7-AAD (Figure 2) on ASCs showed excellent viability rates (range $93.12-97.4 \%$ ) that were comparable among different donor sites (Table II).

\section{Discussion}

Fat grafting has been one of the most popular options in plastic surgery both in the cosmetic and reconstructive field (9), since it significantly aids in restoring soft tissue defects, mainly of small to medium size (10). However, complications such as fat reabsorption and necrosis still remain an issue occurring with a rate of $30 \%$ to $70 \%$ (11, 12). Due to their inherent properties, ASCs have recently attracted an increased interest (13). Their capacity of intense proliferation and differentiation into various cell lineages has been postulated to overcome the complications arising from the fat transplantation itself (14). Previous studies have shown excellent cosmetic results with the use of ASCenriched fat grafts on the breast for reconstruction and augmentation as well as on the face, hip and hands $(5,15)$. 

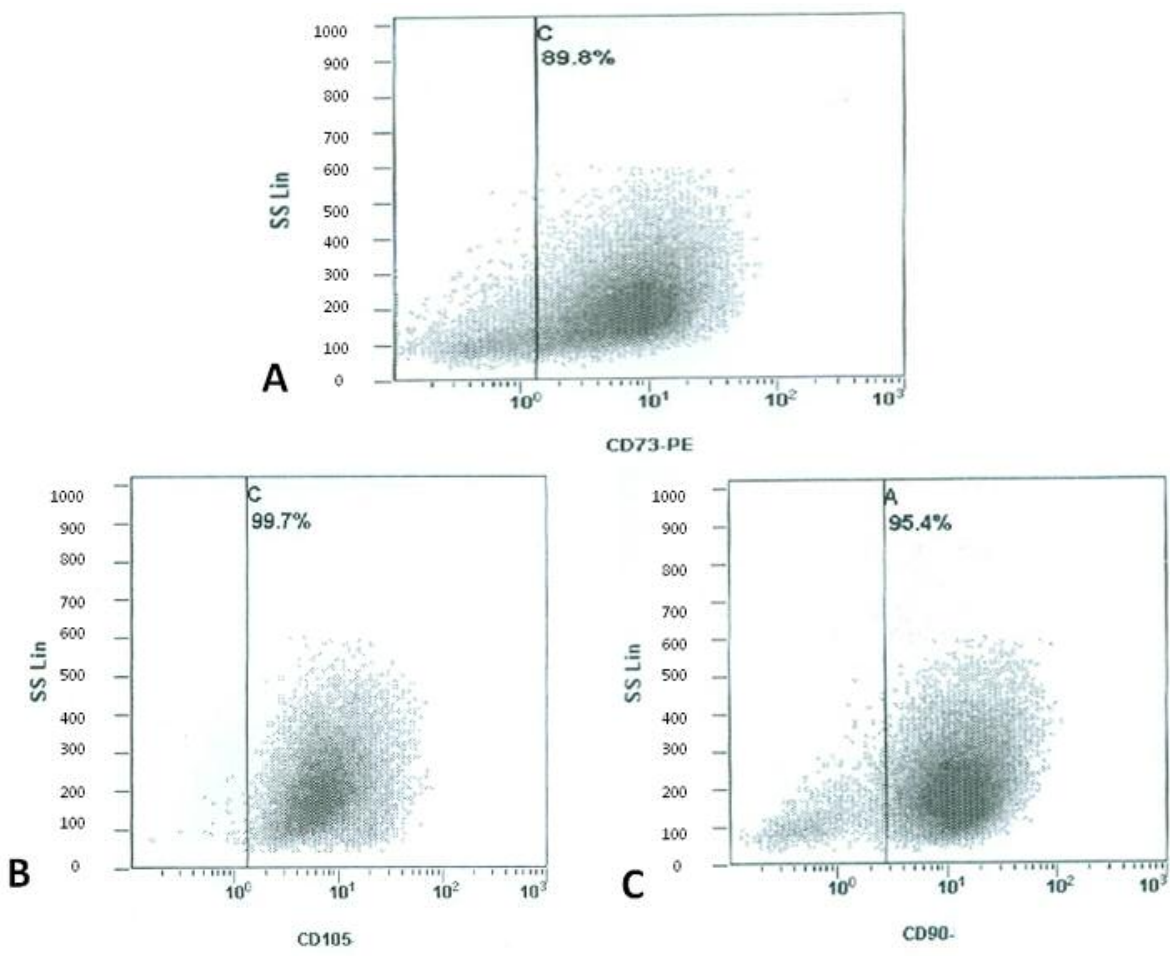

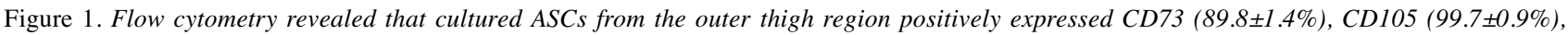
and $C D 90(95.4 \pm 1.3 \%)$

However, there is currently no firm evidence regarding the optimal harvesting area in terms of stem cell yield, proliferation, and differentiation capacity. Therefore, our aim was to examine the effect of the different donor sites on the viability and the yield of stromal and ASCs.

In order to identify ASCs from the SVF, labeling with known stem cell markers was used. We found that cultured ASCs were positive for CD90, CD73, and CD105 and negative for CD45 and CD34. This expression profile is supported by reports from other investigators as well (1618). Cells positive for CD90 and CD105 are defined as mesenchymal stem cells based on the minimal criteria for defining mesenchymal stem cells by the International Society for Cellular Therapy (19).

The investigation of the viability of cells from different donor areas, showed that the average viability of either the SVF cells or the ASCs, was excellent, reaching up to $95 \%$ when tested with Trypan Blue and more than $96 \%$ when tested using 7-AAD on the flow cytometer, respectively. Adipose tissue from the abdomen, waist, thigh and inner knee revealed no significant differences with regard to the viability profile of cells. Superficial abdominal depot has also been shown to less susceptible to apoptosis compared to ASCs from other regions (20). However, we did not

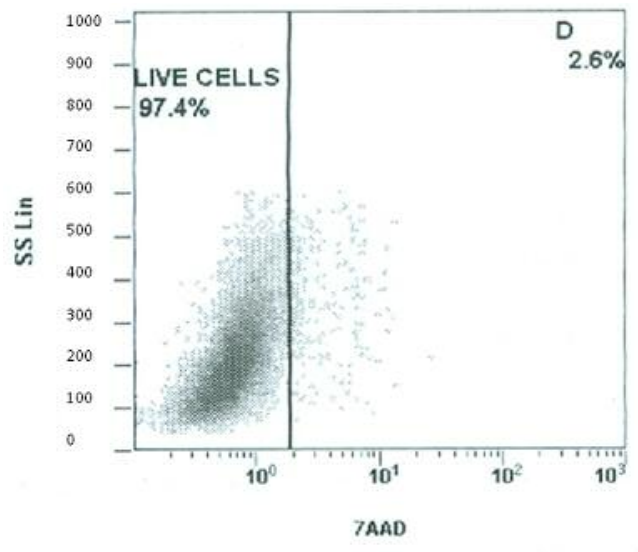

Figure 2. Staining with 7-AAD on ASCs from the outer thigh region showed excellent viability rates $(97.4 \pm 0.7 \%)$.

observe significant differences in viability profiles among donor areas. In our study, we constantly compared cultured ASCs rather than freshly isolated ASCs considering their higher level of homogeneity. Due to the fact that cultured ASCs display minor differences in phenotype and kinetics of differentiation compared to freshly isolated ASCs (21), it can 
be hypothesized that both types of ASCs may exhibit the same viability profile.

When we compared the yield of SVF cells among different donor areas, the outer thigh region the highest yield compared to the other regions. After isolation of the ASCs from the SVF, we also found that the outer thigh region contained higher concentration of ASCs, compared to the abdomen, waist and the inner knee. This is in contrast to a previous study in which the abdomen has appeared as a preferable region for harvesting adipose tissue due to the higher ASCs yield (8).

Literature suggests that except for donor areas, age is another strong determinant of the quality of the ASCs. It has been shown that ASCs from younger patients hold a greater proliferative capacity and are more efficient in differentiating into mature adipocytes than those from older patients (20), rendering younger patients more suitable for tissue engineering applications. In the present study, the mean age was 41.5 years, significantly less than the age group of 5560 that displays the highest apoptotic rates (20).

Finally, proliferation capacity and functionality of ASCs is strongly influenced by the BMI of the patients, showing increased activity in some massively obese patients compared to lean controls (22). Therefore, obese patients $\left(B M I \geq 30 \mathrm{~kg} / \mathrm{m}^{2}\right)$ were excluded from our study and the BMI of our participants was $28 \mathrm{~kg} / \mathrm{m}^{2}$.

\section{Conclusion}

Tissue-harvesting area is a strong determinant of the quality of the fat grafts. Compared to the abdomen, waist and inner knee, thighs seem favorable in terms of viability profile and yield of SVF cells and ASCs. Further randomized controlled trials incorporating a larger cohort of patients are warranted in order to verify our results.

\section{Conflicts of Interest}

None.

\section{References}

1 Stephan PJ and Kenkel JM: Updates and advances in liposuction. Aesthet Surg J 30(1): 83-97; quiz 98-100, 2010.

2 Triana L, Triana C, Barbato $\mathrm{C}$ and Zambrano M: Liposuction: 25 years of experience in 26,259 patients using different devices. Aesthet Surg J 29(6): 509-512, 2009.

3 Schneider S, Unger M, van Griensven M and Balmayor ER: Adipose-derived mesenchymal stem cells from liposuction and resected fat are feasible sources for regenerative medicine. Eur J Med Res 22(1): 17, 2017.

4 Peterson B, Zhang J, Iglesias R, Kabo M, Hedrick M, Benhaim $\mathrm{P}$ and Lieberman JR: Healing of critically sized femoral defects, using genetically modified mesenchymal stem cells from human adipose tissue. Tissue Eng 11(1-2): 120-129, 2005.
5 Tsekouras A, Mantas D, Tsilimigras DI, Ntanasis-Stathopoulos I, Kontos M and Zografos GC: Adipose-derived stem cells for breast reconstruction after breast surgery - preliminary results. Case Reports Plast Surg Hand Surg 4(1): 35-41, 2017.

6 De Ugarte DA, Morizono K, Elbarbary A, Alfonso Z, Zuk PA, Zhu M, Dragoo JL, Ashjian P, Thomas B, Benhaim P, Chen I, Fraser $\mathbf{J}$ and Hedrick MH: Comparison of multi-lineage cells from human adipose tissue and bone marrow. Cells Tissues Organs 174(3): 101-109, 2003.

7 Strem BM, Hicok KC, Zhu M, Wulur I, Alfonso Z, Schreiber RE, Fraser JK and Hedrick MH: Multipotential differentiation of adipose tissue-derived stem cells. Keio J Med 54(3): 132-141, 2005.

8 Jurgens WJ, Oedayrajsingh-Varma MJ, Helder MN, Zandiehdoulabi B, Schouten TE, Kuik DJ, Ritt MJ and van Milligen FJ: Effect of tissue-harvesting site on yield of stem cells derived from adipose tissue: implications for cell-based therapies. Cell Tissue Res 332(3): 415-426, 2008.

9 Rigotti G, Marchi A, Galie M, Baroni G, Benati D, Krampera M, Pasini A and Sbarbati A: Clinical treatment of radiotherapy tissue damage by lipoaspirate transplant: a healing process mediated by adipose-derived adult stem cells. Plast Reconstr Surg 119(5): 1409-1422; discussion 1423-1404, 2007.

10 Simonacci F, Bertozzi N, Grieco MP, Grignaffini E and Raposio E: Autologous fat transplantation for breast reconstruction: A literature review. Ann Med Surg (Lond) 12: 94-100, 2016.

11 Pinski KS and Roenigk HH, Jr: Autologous fat transplantation. Long-term follow-up. J Dermatol Surg Oncol 18(3): 179-184, 1992.

12 Groen JW, Negenborn VL, Twisk DJ, Rizopoulos D, Ket JC, Smit JM and Mullender MG: Autologous fat grafting in oncoplastic breast reconstruction: A systematic review on oncological and radiological safety, complications, volume retention and patient/surgeon satisfaction. J Plast Reconstr Aesthet Surg 69(6): 742-764, 2016.

13 Philips BJ, Marra KG and Rubin JP: Healing of grafted adipose tissue: current clinical applications of adipose-derived stem cells for breast and face reconstruction. Wound Repair Regen 22(Suppl 1): 11-13, 2014.

14 Matsumoto D, Sato K, Gonda K, Takaki Y, Shigeura T, Sato T, Aiba-Kojima E, Iizuka F, Inoue K, Suga $\mathrm{H}$ and Yoshimura K: Cell-assisted lipotransfer: supportive use of human adiposederived cells for soft tissue augmentation with lipoinjection. Tissue Eng 12(12): 3375-3382, 2006.

15 Yoshimura K, Sato K, Aoi N, Kurita M, Hirohi T and Harii K: Cell-assisted lipotransfer for cosmetic breast augmentation: supportive use of adipose-derived stem/stromal cells. Aesthetic Plast Surg 32(1): 48-55; discussion 56-47, 2008.

16 Mafi P, Hindocha S, Mafi R, Griffin M and Khan WS: Adult mesenchymal stem cells and cell surface characterization - a systematic review of the literature. Open Orthop J 5(Suppl 2): 253-260, 2011.

17 Ishimura D, Yamamoto N, Tajima K, Ohno A, Yamamoto Y, Washimi $\mathrm{O}$ and Yamada H: Differentiation of adipose-derived stromal vascular fraction culture cells into chondrocytes using the method of cell sorting with a mesenchymal stem cell marker. Tohoku J Exp Med 216(2): 149-156, 2008.

18 Aust L, Devlin B, Foster SJ, Halvorsen YD, Hicok K, du Laney T, Sen A, Willingmyre GD and Gimble JM: Yield of human adipose-derived adult stem cells from liposuction aspirates. Cytotherapy 6(1): 7-14, 2004. 
19 Dominici M, Le Blanc K, Mueller I, Slaper-Cortenbach I, Marini F, Krause D, Deans R, Keating A, Prockop D and Horwitz E: Minimal criteria for defining multipotent mesenchymal stromal cells. The International Society for Cellular Therapy position statement. Cytotherapy 8(4): 315-317, 2006.

20 Schipper BM, Marra KG, Zhang W, Donnenberg AD and Rubin JP: Regional anatomic and age effects on cell function of human adipose-derived stem cells. Ann Plast Surg 60(5): 538-544, 2008.

21 Varma MJ, Breuls RG, Schouten TE, Jurgens WJ, Bontkes HJ, Schuurhuis GJ, van Ham SM and van Milligen FJ: Phenotypical and functional characterization of freshly isolated adipose tissuederived stem cells. Stem Cells Dev 16(1): 91-104, 2007.

22 Roncari DA, Lau DC and Kindler S: Exaggerated replication in culture of adipocyte precursors from massively obese persons. Metabolism 30(5): 425-427, 1981

Received July 26, 2017

Revised August 16, 2017

Accepted August 31, 2017 